Scientific Journal of Silesian University of Technology. Series Transport Zeszyty Naukowe Politechniki Śląskiej. Seria Transport

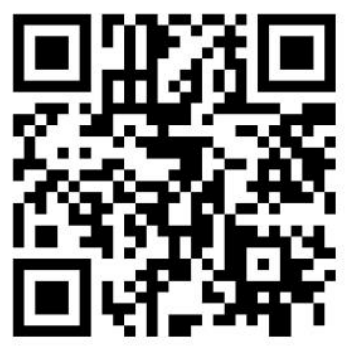

Volume 114

2022

p-ISSN: 0209-3324

e-ISSN: 2450-1549

DOI: https://doi.org/10.20858/sjsutst.2022.114.16

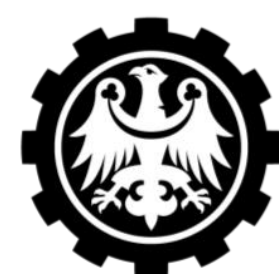

Silesian

University of Technology

Journal homepage: http://sjsutst.polsl.pl

Article citation information:

Ziętala, M. Stability of GPS and GLONASS onboard clocks on a monthly basis. Scientific Journal of Silesian University of Technology. Series Transport. 2022, 114, 193-209.

ISSN: 0209-3324. DOI: https://doi.org/10.20858/sjsutst.2022.114.16.

\author{
Michał ZIETTALA ${ }^{1}$
}

\title{
STABILITY OF GPS AND GLONASS ONBOARD CLOCKS ON A MONTHLY BASIS
}

Summary. This paper presents the stability of the GPS and GLONASS system clocks' stability. It describes the construction of these two systems and calculated four different Allan variances (AVAR), based on the MGEX (the Multi-GNSS Experiment) clock products. Four used variances allowed making a better analysis of each GNSS system clock. The results are shown at different averaging times from $5 \mathrm{~s}$ as successive multiples to $655,360 \mathrm{~s}$ in a monthly period. The stability of GPS and GLONASS clocks is included in the range of 10-12 10-14 s. The results showed that GLONASS clocks are stable (10-12 10-14 s) and are affected with white frequency noise (WFM). The GPS clock stability models have more fluctuations for $\tau>40,960 \mathrm{~s}$ and the mean stability is concluded between 10-12 1013 s. Mean frequency accuracy for GPS clocks is related with WFM and Random Walk Frequency (RWF). The differences in clock stability are caused by several factors - block type, type of clock and the time of a satellite in orbit. These factors have an influence on stability results.

Keywords: GPS, GLONASS, clock, stability analysis, MGEX

\footnotetext{
${ }^{1}$ AGH University of Science and Technology, Mickiewicza 30 Av., 30059 Krakow, Poland. Email: oregal116@wp.pl. ORCID: https://orcid.org/0000-0003-0354-3687
} 


\section{INTRODUCTION}

Currently, GNSS systems are used in many areas of human life, for example, safety, transport, shipping, or in many professions like geodesy, mapping and many other engineering studies (Saleh and Chelouah, 2004; Borowski, 2013; Maciuk et al., 2021; Kawiecka et al., 2018). Precise time measurement is the basis for the operation of GNSS systems and, in addition to the knowledge of satellite coordinates (orbits) allows to determine the user's position (Maciuk, 2016; Novak et al., 2020). The first GNSS system was the American GPS (Global Positioning System), created for military usage and it was not generally available for civil usage. Today, everyone can use GPS and this system plays an important role in many real-life applications. Currently, there are 5 GNSS systems (Rabbou and El-rabbany, 2016; Jakowski, 2017; Saleh and Chelouah, 2004). There is the American GPS (Global Positioning System), Russian GLONASS (Global Navigation Satellite System), European Galileo, Chinese BeiDou, and Japanese QZSS (Ługowska et al., 2011; Perski et al., 2013; Li et al., 2018). The first two mentioned navigation systems were made and became fully operational as firsts so far.

Currently, the GPS space segment consists of 31 satellites from which 4 satellite blocks (IIR IIRM, IIF, III) are in use (Tab. 1), from the 8 satellite blocks manufactured so far. A total of 39 satellites were launched in the already inactive Blocks I, II and IIA. One of the Block I had a launch failure. In the current blocks, 38 satellites were launched into orbit. Again, one of the IIR Block did not perform the mission. The first of the 2R block was launched on July 23, 1997. Since September 25, 2006, an upgraded 2R-M block has been introduced. 2F satellites were launched between 2010 and 2016, while the latest Block III started launches on December 23, 2018 (Quasi-Zenith Satellite System - 2020; Steigenberger, Thoelert, and Montenbruck - 2020). In Block IIIF, launches of satellites will start 2026 and it is planned until 2034 GPS Block IIIF, access date 14 Sep 2021). Tab. 1 shows a total of 30 operational satellites, with 4 satellites in testing/reserve. The 22 satellites in Block IIIF are projected to be delivered from 2026, with launches estimated to last through at least 2034.

Tab. 1.

GPS satellite blocks

\begin{tabular}{|l|c|c|c|c|c|}
\hline Block, New & Launched & $\begin{array}{c}\text { Operation } \\
\text { al }\end{array}$ & $\begin{array}{c}\text { Testing/ } \\
\text { Reserve }\end{array}$ & Retired & $\begin{array}{c}\text { Launch } \\
\text { failures }\end{array}$ \\
\hline Block I & 11 & 0 & 0 & 10 & 1 \\
\hline Block II & 9 & 0 & 0 & 9 & 0 \\
\hline Block IIA & 19 & 0 & 0 & 19 & 0 \\
\hline Block IIR & 13 & 7 & 2 & 3 & 1 \\
\hline Block IIRM & 8 & 7 & 1 & 0 & 0 \\
\hline Block IIF & 12 & 12 & 0 & 0 & 0 \\
\hline Block III & 5 & 4 & 1 & 0 & 0 \\
\hline Block IIIF & 0 & 0 & 0 & 0 & 0 \\
\hline Total & 77 & 30 & 4 & 41 & 2 \\
\hline
\end{tabular}

Source: https://en.wikipedia.org/wiki/GPS_satellite_blocks

GLONASS currently has 26 satellites divided into 7 blocks, of which the 2 operational blocks are GLONASS M and GLONASS K1 (Li et al., 2019). The first satellite, which is in reserve now, was launched on December 25, 2006, and the last had flight tests on October 25, 2020. The new satellites are planned to be launched in 2022, and after that year, the new Block 
K2 will start to launch. Tab. 2 shows the breakdown of GLONASS satellites. Uragan satellites are divided into 7 blocks, of which 2 are currently in use. In the inactive blocks I, IIa, IIb, IIv, III were launched a total of 88 satellites, including from block IIb, 6 were lost during launch. The currently active blocks are Uragan-M and Uragan-K1, where a total of 53 satellites were launched. In version M, 50 satellites were introduced, only 1 is remaining to launch. Currently, only 22 are operational, 1 is not used and 6 were lost at launch. The rest of them are retired. Block $\mathrm{K} 1$ has 3 running satellites, where only 1 is operational and 2 are not used. Further satellites from this block will be launched by 2033 .

Tab. 2.

GLONASS satellite blocks

\begin{tabular}{|l|c|c|c|c|c|}
\hline \multicolumn{1}{|c|}{ Block, New } & Launched & Operational & Not used & Retired & $\begin{array}{c}\text { Launch } \\
\text { failures }\end{array}$ \\
\hline Uragan Block I & 10 & 0 & 0 & 10 & 0 \\
\hline Uragan Block IIa & 9 & 0 & 0 & 9 & 0 \\
\hline Uragan Block IIb & 12 & 0 & 0 & 6 & 6 \\
\hline Uragan Block IIv & 56 & 0 & 0 & 56 & 0 \\
\hline Uragan Block III & 1 & 0 & 0 & 1 & 0 \\
\hline Uragan & 50 & 22 & 1 & 21 & 6 \\
\hline Uragan-K1 & 3 & 1 & 2 & 0 & 0 \\
\hline Total & 141 & 23 & 3 & 103 & 12 \\
\hline
\end{tabular}

Source: https://en.wikipedia.org/wiki/List_of_GLONASS_satellites

GPS and GLONASS differ from each other by several factors. As can be seen in the two tables above, GPS has 7 more operational satellites than GLONASS. For GPS, there are 4 operational blocks, and there are 2 for GLONASS. Historically, the Russian system has launched 141 satellites, which is 64 more than the GPS has launched. These GNSS systems also have technical differences. GPS has better position accuracy, which is 3.5-7.8 m, while GLONASS is 5-10 m (Rutkowski, 2019). In the case of frequencies, GLONASS operates at $1.602 \mathrm{GHz}$, whereas GPS uses the L1 signal, operating at $1.57542 \mathrm{GHz}$ (Yunck et al., 1985; Marin et al., 2017). All GLONASS satellites are equipped with caesium clocks, unlike GPS satellites, where the majority are rubidium clocks. Despite these differences, there is one common factor without which the GNSS systems could not work. It is time, which is the key to work in each GNSS system (Meng et al., 2020). The user position is generated based on the measuring time at which the signals travel from the satellite to the receiver, with the assumption of the known speed of the signal, distance is calculated (Galleani and Tavella, 2015). To make it possible there are precise, atomic clocks onboard each satellite (Daly et al., 1991). These clocks are the basis for all GNSS systems and have an important influence on the accuracy of navigation positioning (Ye et al., 2021; Delporte et al., 2012) Atomic clocks have a high level of stability, but they also have errors. The stability of onboard clocks can change due to several factors like aging, sudden breakdowns, radiations, or temperature, which is why there is no perfect synchronisation between the time of the satellite broadcast signals and the GNSS system time ( $\mathrm{Li}$ et al., 2018). Therefore, it is important to constantly monitor the performance of satellite clocks to improve the work of GNSS systems (Delporte et al., 2012). There are several types of GNSS clocks and each one presents a different performance(Shi et al., 2019; Walter et al., 2018). 
In the case of internal clocks, we have quartz, rubidium, caesium and hydrogen masers (Roberts, 2019). After 2000, the most common were rubidium clocks because of their lower costs (Brouwer, 1951). Authors in several articles have provided research on GNSS clock performance and described the differences in stability between some satellite blocks. As research shows, the highest stability was confirmed on rubidium clocks of GPS Block IIA. The rubidium clocks from Block IIA had lower noise than the clocks from newer Blocks IIR and IIRM for $\tau$ up to $100 \mathrm{~s}$ (Hauschild et al., 2013). Furthermore, Block IIA granted greater stability than GPS Block IIA and IIF caesium clocks (Thoelert et al., 2014). Whereas GLONASS uses caesium clocks, which reveal similar stability as GPS Block IIA caesium clocks and rubidium clocks from IIR and IIRM at $\tau$ above 20 s (Griggs et al., 2014; Xu and Xu, 2016)

In this paper, GPS satellites are mostly equipped with the rubidium type, only numbers 8 and 24 have caesium clocks. The results show that caesium clocks from GPS Block IIF present lower stability $\left(10^{-12} \sim 10^{-13} \mathrm{~s}\right)$ than some of the GPS rubidium clocks $\left(10^{-12} \sim 10^{-14} \mathrm{~s}\right)$. The GLONASS clocks are all caesium type, and their stability is in $\left(10^{-12} \sim 10^{-14} \mathrm{~s}\right)$ level. To estimate the stability of GNSS clocks, the author made a frequency stability analysis. Already in the mid-1960's, the new modern frequency stability analysis has begun. In those days, new statistics that could better suit common clock noises became available and better methods were developed for high-resolution measurements (Nistor, 2016). The new era started in 1966 when the introduction of the two sample Allan variance was summarised by (Stefani 2004). Since then, we can calculate and illustrate variations with the time of the clock stability with Allan (and related) Variances (Galleani and Tavella, 2015). These variances can be related to phase noise power spectral density (Nistor and Buda, 2016). There are many works about the stability of GNSS onboard clocks and related problems (Xie et al., 2019; Yang et al., 2019; Lyu et al., 2020; Li et al., 2019; Montenbruck et al., 2017; Shi et al., 2019; Li et al., 2018). In this paper, research was conducted on the subject.

This article examined the stability of GPS and GLONASS clocks on a monthly basis (1-31 January 2021), based on a $30 \mathrm{~s}$ sampling interval. Clock stabilities are measured based on phaseto-frequency data conversion using variances (Huang et al., 2019). In the methods section are used four types: Allan deviation (ADEV), Overlapping Allan (ODEV), Modified Allan (MDEV) and Hadamard Allan deviation (HDEV) variances that have been analysed and described respectively by formulas (2)-(5). In this paper, are explored types of power-law noises, which are presented in Tables 3 and 4 . The calculations of variances are related with types of noise, as described and presented in Figures 3-10.

\section{METHODS}

In this paper, the author analysed short-term satellite clock stability (in terms of 1 month) of two fully operational GNSS - GPS and GLONASS. The special calculations of a few variances were done to obtain better certainty of the analysis.

Variances are used to characterise fluctuations in the frequency domain. The most common time domain measure of frequency stability is the classic Allan Variance (AVAR) and there are also related versions (variances), that provide better confidence or have other specifications (Stefani, 2004). The Allan (and related) variances allow analysing the stability of atomic clocks, including GPS and GLONASS satellites (Zucca and Tavella, 2005; Galleani and Tavella, 2009; Gambis, 2002). Equation (1) presents frequency data $y_{i}$ as the difference of the phase data $x_{i}$ and dividing them by the sampling interval $\tau$ : 


$$
y_{i}=\frac{x_{i+1}-x_{i}}{\tau}
$$

The formula needed to determine the variance are shown in Figure 1. The $x(t)$ function presents a simulated plot of time fluctuations calculated from frequency data y_i. At the bottom left, are equations for the standard deviation, and at the bottom right are equations, through which we can determine stability in the field of time ("Section Four", 1980). The y_i in those calculations is the ith of $\mathrm{M}$ fractional frequency values. The $\tau$ interval is the time in which the data is averaged and analysed.

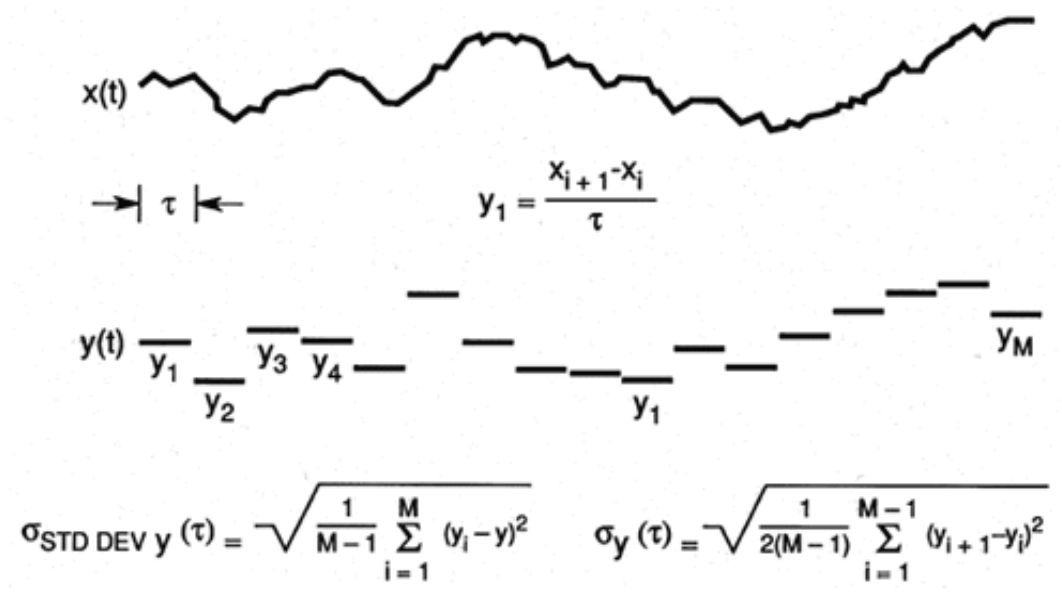

Fig. 1. Graphical interpretation of standard deviation vs Allan deviation

(Howe and Allan and Barnes, 1999)

There are several versions of Allan variance that provide greater statistical accuracy or allow the determining of other noises. In this paper, the author uses the classic Allan deviation (ADEV), overlapping Allan deviation (ODEV) and Modified Allan deviation (MDEV) and Hadamard Allan deviation (HDEV) (Howe and Peppler, 2001). The classic ADEV is the most common variance type used to measure frequency stability. It has the advantage of being convergent for most types of clock noises. Allan's deviation is expressed as equation (2):

$$
\sigma_{y}^{2}(\tau)=\frac{1}{2(M-1)} \sum_{i=1}^{M-1}\left(y_{i+1}-y_{i}\right)^{2}
$$

ODEV variance, $\sigma_{y}^{2}(\tau)$, provides more confidence than Allan's classic variance. It uses sample overlap during averaging time $\tau$, which improves the certainty of estimating the resulting stability. It can be estimated from a set of $M$ frequency measurement for averaging time $\tau=m_{\tau_{0}}$, where $m$ is the averaging factor and is the basic measurement $\tau_{0}$ interval (Stefani, 2004). The disadvantage of this type of variance is the longer calculation time. Overlapping Allan variance can be obtained from the formula:

$$
\sigma_{y}^{2}(\tau)=\frac{1}{2 m^{2}(M-2 m+1)} \sum_{j=1}^{M-2 m+1} \sum_{i=j}^{j+m-1}\left(y_{i+m}-y_{i}\right)^{2}
$$


The modified Allan variance type is used to distinguish between white noise and flicker PM (Phase Modulation) and can be expressed as equation (4):

$$
\operatorname{Mod}_{y}^{2}(\tau)=\frac{1}{2 m^{4}(M-3 m+2)} \sum_{j=1}^{M-3 m+2}\left\{\sum_{i=j}^{j+m-1}\left(\sum_{k=i}^{i+m-1}\left(y_{k+m}-y_{k}\right)\right)\right\}^{2}
$$

Hadamard's variance is characterised by insensitivity to linear drift. It has a much narrower transfer function, making it useful for the analysis of rubidium atomic clocks (Stefani, 2004). Hadamard variance can be calculated using the formula:

$$
H \sigma_{y}^{2}(\tau)=\frac{1}{6(M-2)} \sum_{i=1}^{M-2}\left[y_{i+2}-2 y_{i+1}+y_{i}\right]^{2}
$$

The noise power spectral density determines the stability of a satellite's clock. Power-law noises have a spectral density of their fractional frequency fluctuations of the form $S_{y}(f) \propto f^{\alpha}$, where $f$ is the frequency in hertz, and $\alpha$ is the power-law exponent (Xu and Yue, 2017; Stefani, 2004). The author suited the four used variances with noises, estimated the stability and modelled it in Figures 3-10 (Griggs et al., 2015). Several types of noise are shown in Tab. 3 together with an exponent corresponding to a given type. In this article, calculated variances from GPS and GLONASS clocks were associated with WFM and RWF.

Tab. 3 .

Type of noise

\begin{tabular}{|l|c|}
\hline \multicolumn{1}{|c|}{ Type of noise } & $\alpha$ \\
\hline White PM & 2 \\
\hline Flicker PM & 1 \\
\hline White FM & 0 \\
\hline Flicker FM & -1 \\
\hline Random Walk FM & -2 \\
\hline Flicker Walk FM & -3 \\
\hline Random Run FM & -4 \\
\hline
\end{tabular}

Figure 2 shows noise types detected by ODEV and MDEV. An additional advantage of Allan's modified variance is that one can distinguish white phase and flicker phase noise.

In this paper, Allan (and related) variations were calculated based on the MGEX (the MultiGNSS Experiment) clock products. Time span covers the first 31 days of the year 2021 (1st-31st January). Daily 30 s clock products for GPS and GLONASS observations were combined and based on equations 1-5, for each GNSS system were calculated four different types of the Allan variations for combined clock products for the whole GPS and GLONASS space segment separately. Moreover, on each graph were added a graph with noises characterising each space segment. 

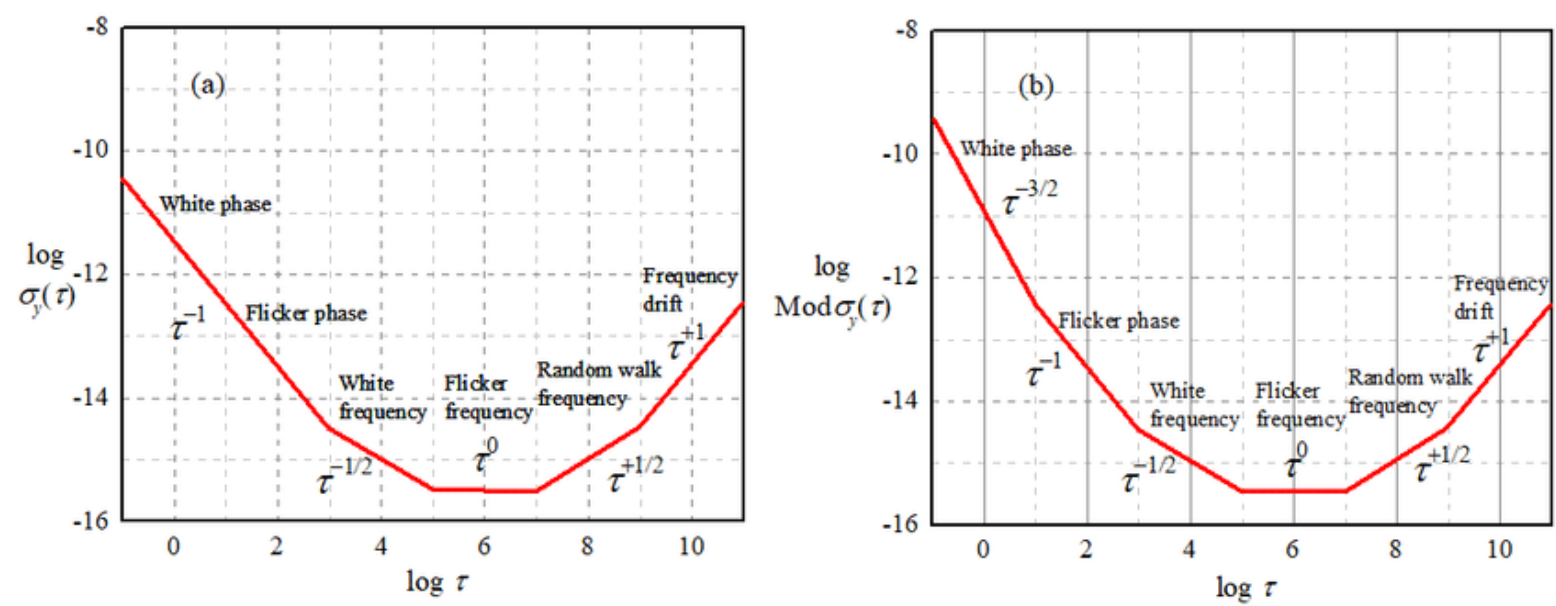

Fig. 2. Noise type graphs detected by the overlapping Allan deviation (left) and the modified Allan deviation (right)

(Physique and Lasers, 2019)

\section{RESULTS}

A total of 8 figures was presented showing the stability of GPS and GLONASS clocks using 4 different types of Allan's variances. The stability is shown at different averaging times from 5 as successive multiples to 655,360 seconds. The clock stability was calculated for 32 GPS satellites from four operational blocks: IIR, IIRM, IIF and III. The oldest operational satellite is from Block IIR, and it has been orbiting for 24 years (since 1997). In the GLONASS case, calculations were made for 21 satellites from blocks M and K1. The oldest satellite has been flying for over 14 years (since 2007).

Figures 3 and 4 present values of ADEV. In Figure 3, we related mean-variance (yellow line) to white frequency modulation (WFM) in the range of $5<\tau<40,960 \mathrm{~s}$. WFM is marked with a longer dashed black line and random walk frequency (RWF) is presented with a dotted black line. We can see that stability fluctuates for $\tau>40,960 \mathrm{~s}$ and its connection with (RWF). The GPS clocks stability is increasing from level 10-12 s to 10-14 $\mathrm{s}$ in the range of $\tau=5 \mathrm{~s}$ to $\tau$ $=40,960 \mathrm{~s}$, and for $\tau>40,960 \mathrm{~s}$, the stability drops to $10-13 \sim 10-12 \mathrm{~s}$. It is mostly visible for satellites G14, G23, G32.

Figure 4 shows GLONASS clocks stability using ADEV. Mean-variance is related with WFM and stability is about 10-12 10-13 s for $5<\tau<40,960 \mathrm{~s}$, and for $\tau>40,960 \mathrm{~s}$, it is increasing even to 10-14 s. We can see that the three clocks from satellites R11, R13, R2 have worse stability compared to the others and R11 has a fluctuating frequency drift. The rest GLONASS clocks stabilities are close to each other and the lines presenting frequency accuracy have a similar course.

Figures 5 and 6 present stability results using HDEV. As the charts show, for both GPS and GLONASS satellites, the mean stability has convergence with WFM. In Figure 5, it is visible that stability fluctuates respectively after $\tau>40,960 \mathrm{~s}$. It is shown that GPS satellites, G24 and G8 have worse stability, which is caused by the caesium clock type, for $\tau=5 \mathrm{~s}$, it is between $10-11 \sim 10-12 \mathrm{~s}$, and it rises to $10-13 \mathrm{~s}$ for $\tau=655,360 \mathrm{~s}$. The clocks from satellites G27 and G30 reach the best stability, which is $10-15$ at $\tau=655,360 \mathrm{~s}$. The mean frequency drift for GPS clocks increases from 10-12 to 10-14 s, respectively, with $\tau$ increase. 


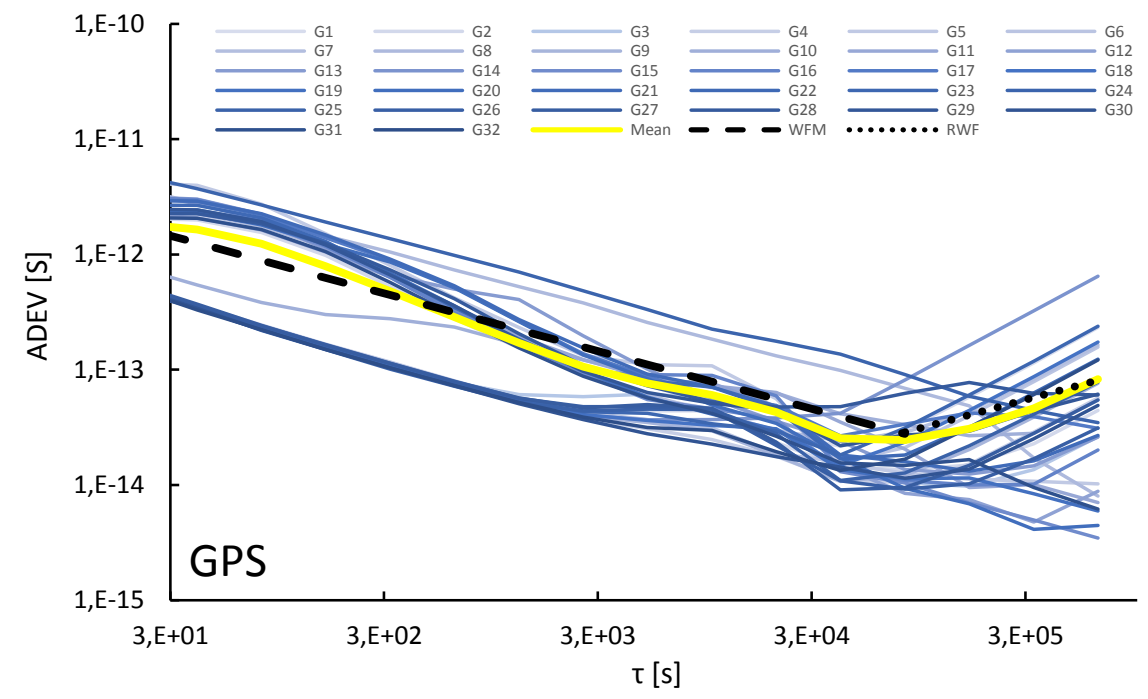

Fig. 3. ADEV of GPS space segment with mean value (yellow line) and assigned noise types (black lines)

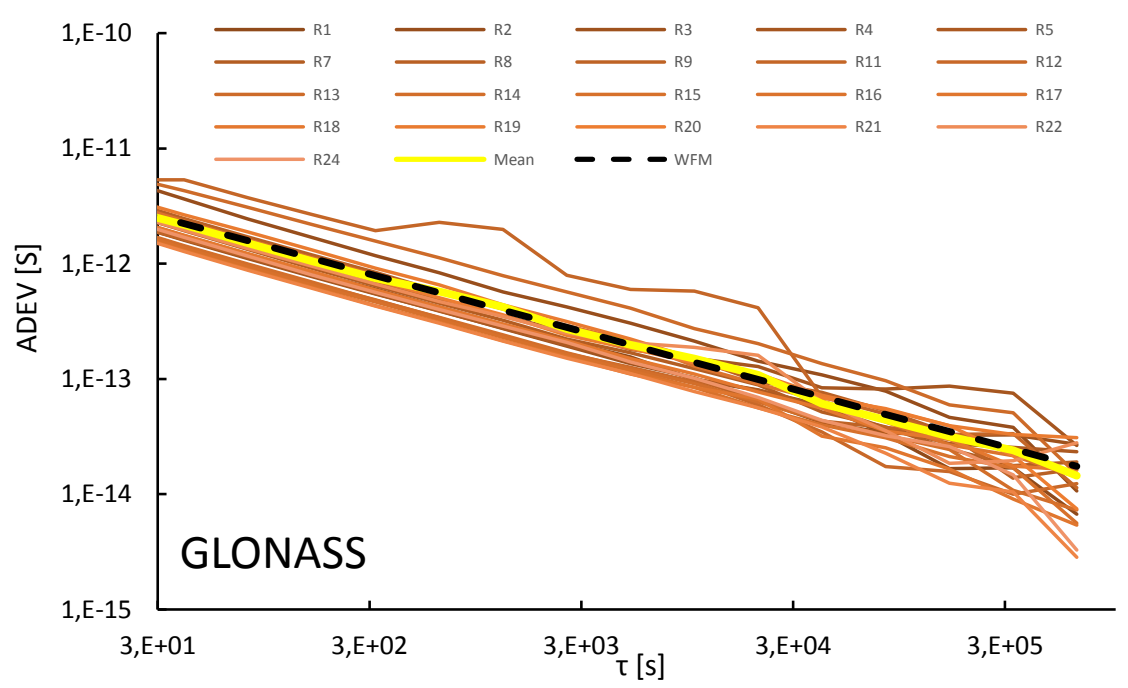

Fig. 4. ADEV of GLONASS space segment with mean value (yellow line) and assigned noise types (black lines)

Whereas in Figure 6, there are lower fluctuations compared to the GPS drift. We also can see fluctuations after $\tau=40,960 \mathrm{~s}$, but they are not as high as GPS ones. The mean stability drift is associated with WFM. GLONASS clocks stability is between 10-11 10-12 s for $\tau=5 \mathrm{~s}$, and it increases to the range of 10-13 10-14 s at $\tau=655,360 \mathrm{~s}$. Further, it should be noted that the clock from the R21 satellite reaches the best 10-15 s stability at the end of $\tau$ range. The differences in stability between the HDEV and ADEV methods are little for GLONASS satellites. 


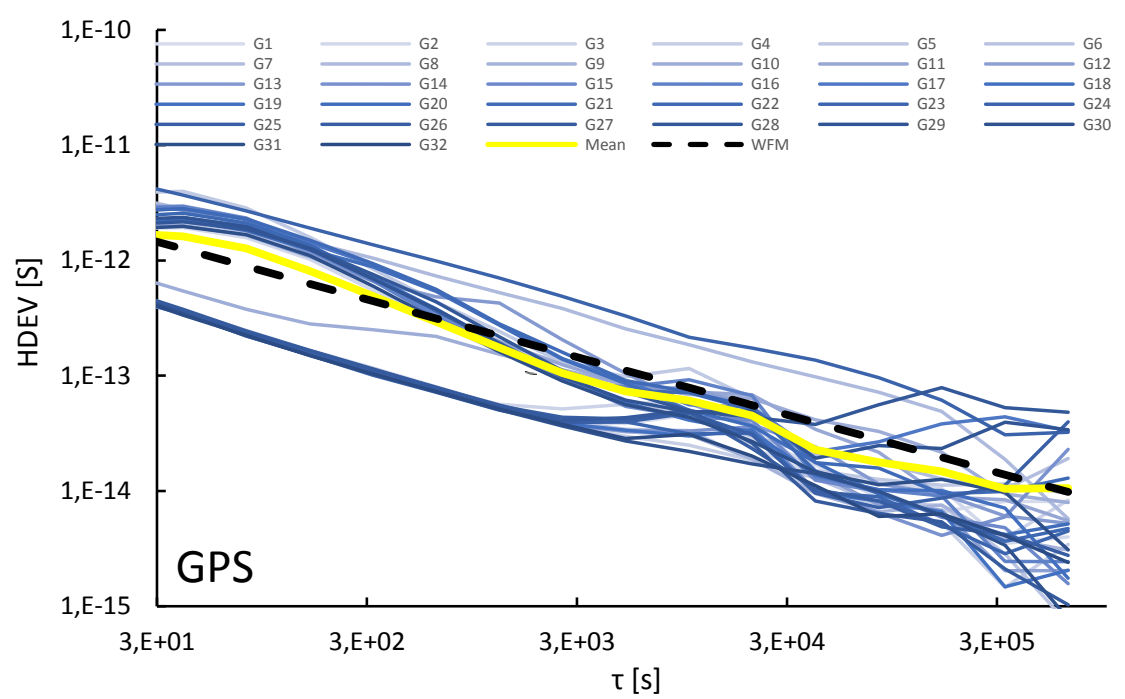

Fig. 5. HDEV of GPS space segment with mean value (yellow line) and assigned noise types (black lines)

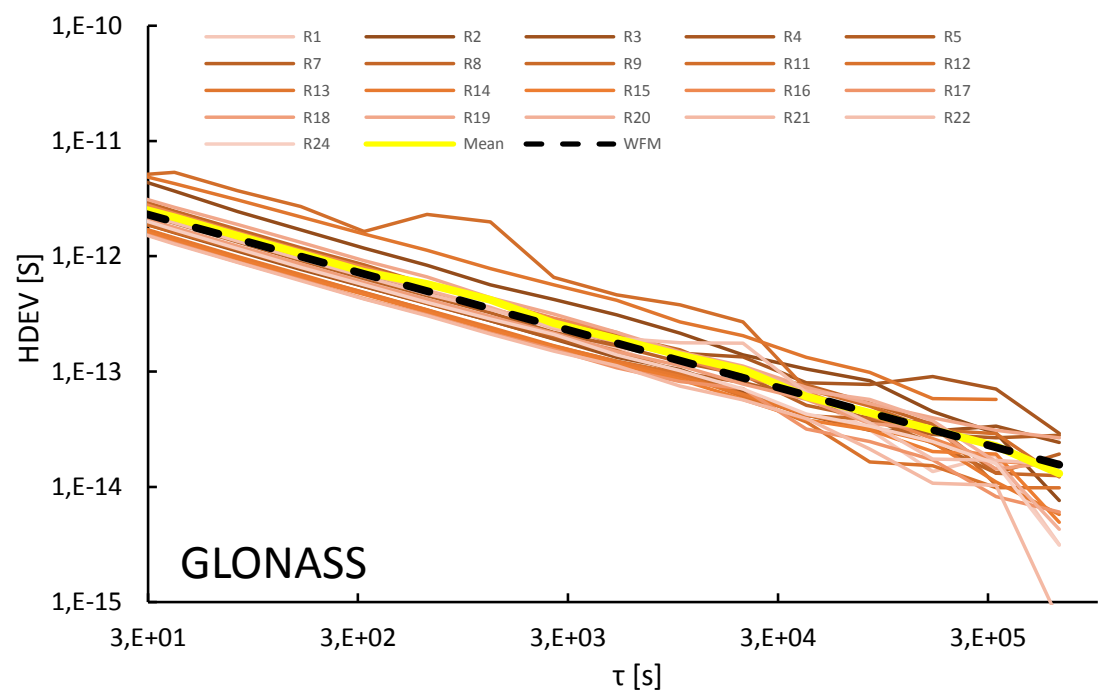

Fig. 6. HDEV of GLONASS space segment with mean value (yellow line) and assigned noise types (black lines)

The next two charts represent clock stability after modified Allan variance. We can see a similar stability model in this method and ADEV. In Figure 7, mean-variance is fitted with WFM and RWF noises. It is visible that half of the GPS clocks have worse stability, which is close to 10-12 s, and the rest have better stability on the level between 10-12 10-13 s, where 5 $<\tau<1.280 \mathrm{~s}$. The biggest changes in line course begin for $\tau>40,960 \mathrm{~s}$, where the fluctuation starts, and the stability result drops from 10-13 to 10-12 s for the clock from Satellite G14. Mean frequency accuracy of GPS satellite clocks starts at level 10-12 s for $\tau=5 \mathrm{~s}$ and reach almost $10-14 \mathrm{~s}$ for $\tau=40,960 \mathrm{~s}$, and then decrease, respectively, to $10-13 \mathrm{~s}$. 


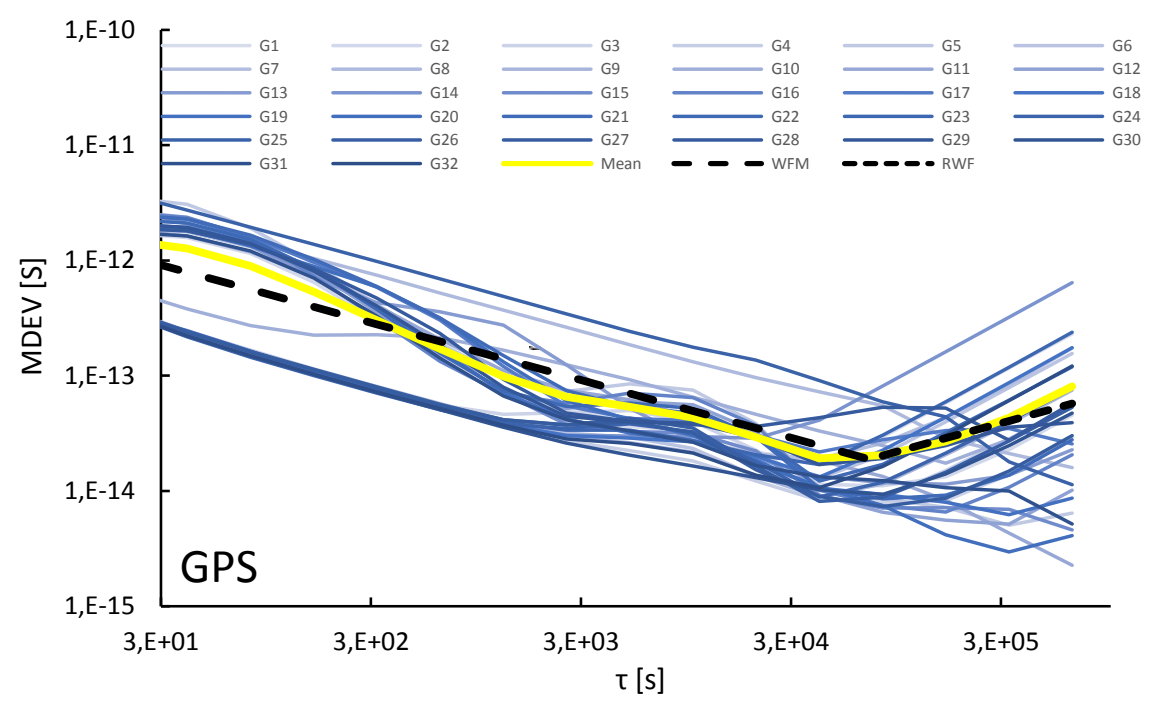

Fig. 7. ADEV of GPS space segment with mean value (yellow line) and assigned noise types (black lines)

In Figure 8, we can see GLONASS clock stability and again it has a more uniform course than the GPS. Similarly, in the MDEV method, it is visible that the clocks frequency accuracy slowly getting better from 10-12 to 10-14 s, respectively, with $\tau$ increase. The stability is slightly better at $\tau=5 \mathrm{~s}$ than it was in HDEV and ADEV variations. The stability of the R11 satellite clock stands out from the rest mostly in the range $320<\tau<20,480 \mathrm{~s}$, and it is around 10-12 s. The mean-variance has convergence with WFM in the studied $\tau$ range.

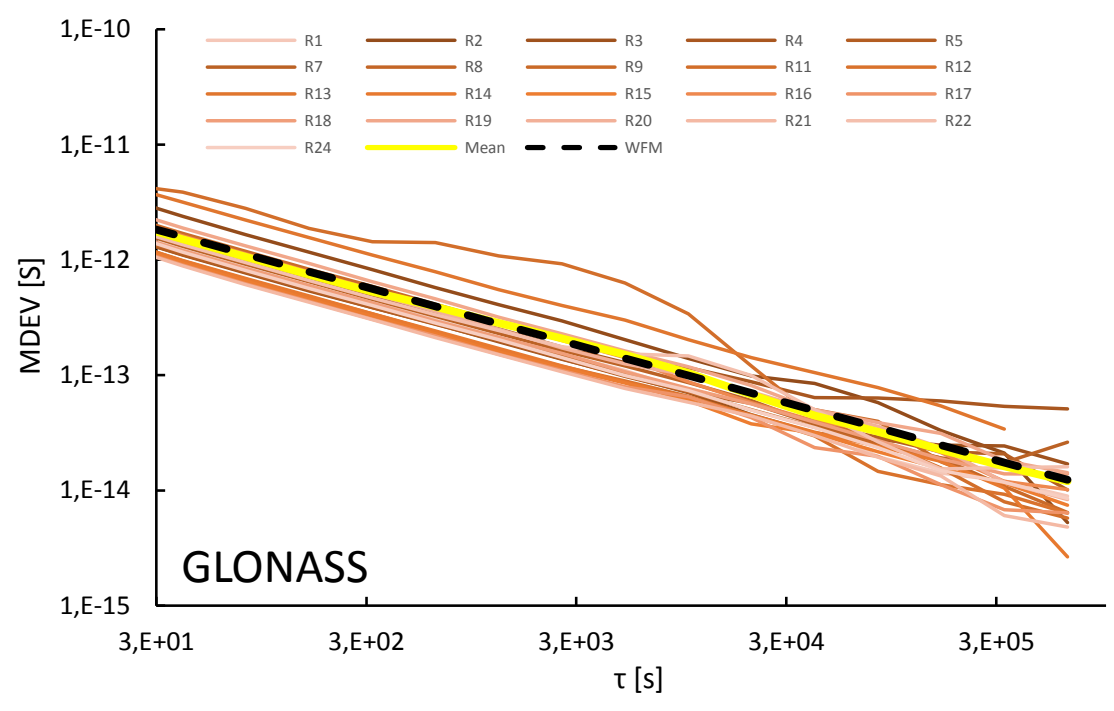

Fig. 8. MDEV of GLONASS space segment with mean value (yellow line) and assigned noise types (black lines)

The last type of variation used by the author is the ODEV variance. Figure 9 shows a similar stability model of GPS clocks to the rest Allan variances. The difference between the clock G24 with the worst stability, and presenting the higher accuracy G30, is 10-1 s in the range where 5 $<\tau<40,960 \mathrm{~s}$. The divergence between these two clocks is caused by the time each satellite is 
in orbit and also, the clock type is the reason. The higher fluctuations in stability are visible after $\tau>40,960 \mathrm{~s}$, where the differences in stability between satellites grow, and the most reach 10-2 s for G14 and G20 satellites. The mean-variance has convergence with WFM and RWF noises.

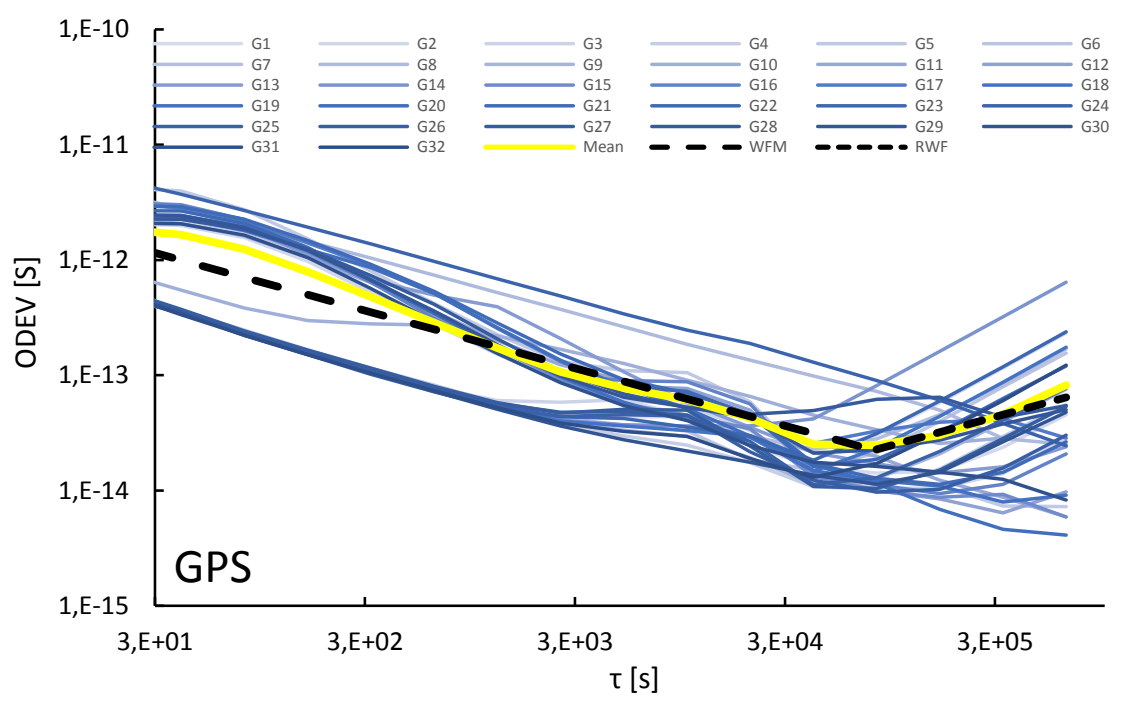

Fig. 9. ODEV of GPS space segment with mean value (yellow line) and assigned noise types (black lines)

In Figure 10, we can see the similar GLONASS clock stability fitted to WFM noise as in previous related variances. The last variation method again shows sticked linear drift, the most similar to the MDEV variance model. Fluctuations after $\tau>40,960 \mathrm{~s}$ seconds are not that much visible as they were in the ADEV and HDEV variations. The most visible difference between the lowest stability R11 satellite clock and the highest accuracy R21 is almost 10-1 s in the range $2,560<\tau<5,120 \mathrm{~s}$. The mean stability for GLONASS clocks using the ODEV method concluded between 10-11 10-12 s for $\tau=5 \mathrm{~s}$, and then increase, respectively, with time to level $10-13 \sim 10-14 \mathrm{~s}$ at $\tau=655,360 \mathrm{~s}$.

Table 4 shows individual values of clock stability depending on the variance type and the GNSS system. It is visible that as with $\tau$ multiplies, the stability of clocks is increasing. In the range $10<\tau<2,560 \mathrm{~s}$, the accuracy of clocks stands on level 10-12 10-13 $\mathrm{s}$. As the $\tau$ increase to $40,960 \mathrm{~s}$ and then gets $655,360 \mathrm{~s}$, the stability is improving up to $10-14 \mathrm{~s}$ and stands on a similar level. It should be noticed that the mean stability of GPS is higher for each variance used than GLONASS clocks, where $10<\tau<40,960 \mathrm{~s}$. The change appears at $\tau=163,840 \mathrm{~s}$, where GLONASS has better accuracy than GPS using MDEV, and at $\tau=655,360 \mathrm{~s}$ GLONASS presents higher stability than GPS clocks for ADEV, MDEV and ODEV.

The presented figures show us the differences in the stability of GLONASS and GPS satellite clocks. We can conclude that GLONASS figures present a more consistent course of variations than the GPS figures. In the GPS, the fluctuations and differences between some satellite frequency stabilities are more visible and its mean stability is associated with WFM and RWF for 3 variances. The GLONASS clock stability is related only to WFM for 4 used variations. The mean stability for both satellite systems clocks is similar and varies in the range 10-12 10$13 \mathrm{~s}$ for GPS and 10-12 10-14 s for GLONASS clocks. From the four methods of variances 
used, the most distinctive stability model for GPS is HDEV, while the rest three are similar. Whereas for GLONASS, we can see the resemblance in the various models between ADEV and HDEV and between MDEV and ODEV.

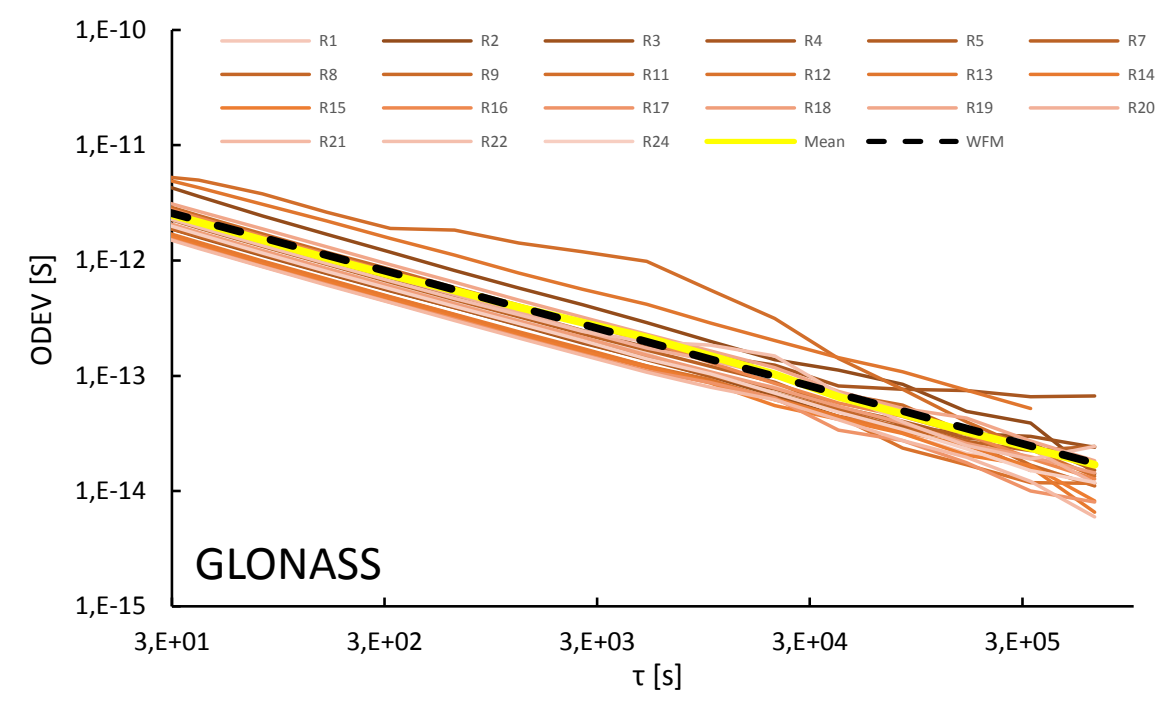

Fig. 10. ODEV of GLONASS space segment with mean value (yellow line) and assigned noise types (black lines)

Tab. 4.

GPS and GLONASS mean clock stability determined by ADEV, HDEV, MDEV, ODEV deviations for selected averaging times

\begin{tabular}{|c|c|c|c|c|c|c|c|c|c|c|}
\hline Variance & System & $10 \mathrm{~s}$ & $40 \mathrm{~s}$ & $160 \mathrm{~s}$ & $640 \mathrm{~s}$ & $2,560 \mathrm{~s}$ & $10,240 \mathrm{~s}$ & $40,960 \mathrm{~s}$ & $163,840 \mathrm{~s}$ & $655,360 \mathrm{~s}$ \\
\hline \multirow{2}{*}{$\mathrm{ADE}$} & GPS & $\begin{array}{r}944 \mathrm{E}- \\
12 \\
\end{array}$ & $\begin{array}{r}65 \mathrm{E}- \\
12 \\
\end{array}$ & $\begin{array}{r}92 \mathrm{E}- \\
13 \\
\end{array}$ & $\begin{array}{r}87 \mathrm{E}- \\
13 \\
\end{array}$ & $\begin{array}{r}1.06 \mathrm{E}- \\
13 \\
\end{array}$ & $\begin{array}{r}6.03 \mathrm{E}- \\
14\end{array}$ & $\begin{array}{r}2.55 \mathrm{E}- \\
14\end{array}$ & $3.07 \mathrm{E}-14$ & $8.26 \mathrm{E}-14$ \\
\hline & GLONASS & $\begin{array}{r}4.383 \mathrm{E}- \\
12 \\
\end{array}$ & $\begin{array}{r}2.17 \mathrm{E}- \\
12\end{array}$ & $\begin{array}{r}1.06 \mathrm{E}- \\
12\end{array}$ & $\begin{array}{r}5.71 \mathrm{E}- \\
13\end{array}$ & $2.7 \mathrm{E}-13$ & $\begin{array}{r}1.49 \mathrm{E}- \\
13\end{array}$ & $\begin{array}{r}6.11 \mathrm{E}- \\
14 \\
\end{array}$ & $3.16 \mathrm{E}-14$ & $1.45 \mathrm{E}-14$ \\
\hline \multirow{2}{*}{ HDEI } & GPS & $\begin{array}{r}1.76 \mathrm{E}- \\
12\end{array}$ & $\begin{array}{r}1.62 \mathrm{E}- \\
12\end{array}$ & $\begin{array}{r}8.13 \mathrm{E}- \\
13\end{array}$ & $\begin{array}{r}2.95 \mathrm{E}- \\
13\end{array}$ & $\begin{array}{r}06 \mathrm{E}- \\
13 \\
\end{array}$ & $\begin{array}{r}6.07 \mathrm{E}- \\
14\end{array}$ & $\begin{array}{r}2.27 \mathrm{E}- \\
14\end{array}$ & $1.48 \mathrm{E}-14$ & $1.06 \mathrm{E}-14$ \\
\hline & GLO & $\begin{array}{r}4.39 \mathrm{E}- \\
12\end{array}$ & \begin{tabular}{r|}
$2.17 \mathrm{E}-$ \\
12
\end{tabular} & \begin{tabular}{r|}
$1.06 \mathrm{E}-$ \\
12
\end{tabular} & $\begin{array}{r}5.73 \mathrm{E}- \\
13\end{array}$ & $\begin{array}{r}2.63 \mathrm{E}- \\
13\end{array}$ & $\begin{array}{r}1.39 \mathrm{E}- \\
13\end{array}$ & $\begin{array}{r}6.09 \mathrm{E}- \\
14\end{array}$ & 3.13 & 1.3 \\
\hline \multirow{2}{*}{ MDE } & GPS & $\begin{array}{r}1.645 \mathrm{E}- \\
12\end{array}$ & $\begin{array}{r}1.27 \mathrm{E}- \\
12\end{array}$ & $\begin{array}{r}5.35 \mathrm{E}- \\
13\end{array}$ & $\begin{array}{r}1.71 \mathrm{E}- \\
13\end{array}$ & $\begin{array}{r}6.54 \mathrm{E}- \\
14\end{array}$ & $\begin{array}{r}4.34 \mathrm{E}- \\
14\end{array}$ & $\begin{array}{r}1.92 \mathrm{E}- \\
14\end{array}$ & $2.7 \mathrm{E}-14$ & $08 \mathrm{E}-14$ \\
\hline & GLONASS & $\begin{array}{r}3.412 \mathrm{E}- \\
12\end{array}$ & $\begin{array}{r}1.51 \mathrm{E}- \\
12\end{array}$ & $\begin{array}{r}7.42 \mathrm{E}- \\
13\end{array}$ & $\begin{array}{r}3.93 \mathrm{E}- \\
13\end{array}$ & $\begin{array}{r}2.08 \mathrm{E}- \\
13\end{array}$ & $\begin{array}{r}1.04 \mathrm{E}- \\
13\end{array}$ & $\begin{array}{r}4.45 \mathrm{E}- \\
14\end{array}$ & $2.25 \mathrm{E}-14$ & $1.2 \mathrm{E}-14$ \\
\hline \multirow{2}{*}{ ODE } & GPS & $\begin{array}{r}1.948 \mathrm{E}- \\
12\end{array}$ & $\begin{array}{r}1.65 \mathrm{E}- \\
12\end{array}$ & $\begin{array}{r}7.91 \mathrm{E}- \\
13\end{array}$ & $\begin{array}{r}2.87 \mathrm{E}- \\
13\end{array}$ & $\begin{array}{r}1.08 \mathrm{E}- \\
13\end{array}$ & $\begin{array}{r}6.14 \mathrm{E}- \\
14\end{array}$ & $\begin{array}{r}2.52 \mathrm{E}- \\
14\end{array}$ & $3.03 \mathrm{E}-14$ & $8.21 \mathrm{E}-14$ \\
\hline & GLONASS & $\begin{array}{r}4.382 \mathrm{E}- \\
12\end{array}$ & $\begin{array}{r}2.15 \mathrm{E}- \\
12\end{array}$ & $\begin{array}{r}1.06 \mathrm{E}- \\
12\end{array}$ & $\begin{array}{r}5.49 \mathrm{E}- \\
13\end{array}$ & $\begin{array}{r}2.89 \mathrm{E}- \\
13\end{array}$ & $\begin{array}{r}1.49 \mathrm{E}- \\
13\end{array}$ & $\begin{array}{r}6.58 \mathrm{E}- \\
14\end{array}$ & $3.26 \mathrm{E}-14$ & 1.69E-14 \\
\hline
\end{tabular}




\section{DISCUSSION}

In this article, GPS and GLONASS clocks stability were analysed. Four variances Allan (and related) were calculated based on the MGEX clock products. Operational satellites from two GNSS systems were chosen for this research and each satellite clock performance was presented at different averaging times, from 5 as successive multiples to $655,360 \mathrm{~s}$. The analysed 32 satellites from GPS concluded mean stability between 10-12 10-13 s and influenced WFM and RWF. The exception was HDEV calculation, where mean variation was associated with WFM, and the stability was approximately 10-12 10-14. The 21 GLONASS satellites also had stability at the level 10-12 10-14 s and were related with WFM noise. The main differences between these two systems are that GLONASS clocks frequency is more consistent, and stability improves with averaging time increasing, whereas GPS clocks are not as compatible as their Russian counterpart, having higher fluctuations for $\tau=40,960 \mathrm{~s}$ and above. The reason for these differences is that GLONASS satellites use only caesium atomic clocks free from frequency drift. The differences between some GPS satellite clocks are visible in the range $5<\tau<1,280 \mathrm{~s}$, where half of all satellites have better stability about 10 times than the others. This may be caused by the different times that each satellite is in orbit. This means that the satellites from older blocks have worse stability than the recently launched ones. From the four variances calculated for GPS clocks, three of them gave very similar results. Only HDEV variation differs more from the others, cause its stability consists of averaging time increasing also after $\tau=40,960 \mathrm{~s}$, and it is only affected by the WFM noise. For GLONASS satellite clocks, the ADEV and HDEV variations showed higher fluctuations. Whereas the other two methods, ODEV and MDEV, presented similar and more consistent stability. The analyses showed that the mean stability of the presented GNSS system clocks is on a similar level, but GLONASS is more stable and consistent. Four calculated variances were compared to each other and allowed for even deeper analysis.

\section{References}

1. Borowski Łukasz. 2013. "Duration of Static GPS Measurements and It's Influence on the Coordinates Accuracy". Budownictwo i Architektura 12(4): 251-56. DOI: https://doi.org/10.35784/bud-arch.1979.

2. Brouwer Dirk. 1951. "The Accurate Measurement of Time". Physics Today 4(8): 6-15. DOI: https://doi.org/10.1063/1.3067337.

3. Daly P., I.D. Kitching, D.W. Allan, T.K. Peppler. 1991. "Frequency and Time Stability of GPS and GLONASS Clocks". In: 44th Annual Symposium on Frequency Control 9: 127-139. IEEE. DOI: https://doi.org/10.1109/FREQ.1990.177490.

4. Delporte Jerome, Cyrille Boulanger, Flavien Mercier. 2012. "Short-Term Stability of GNSS on-Board Clocks Using the Polynomial Method”. In: 2012 European Frequency and Time Forum: 117-121. IEEE. DOI: https://doi.org/10.1109/EFTF.2012.6502347.

5. Galleani Lorenzo, Patrizia Tavella. 2009. "Fast Computation of the Dynamic Allan Variance". 2009 IEEE International Frequency Control Symposium Joint with the 22nd European Frequency and Time Forum 56(3): 685-687.

DOI: https://doi.org/10.1109/FREQ.2009.5168270.

6. Galleani L., P. Tavella. 2015. "The Dynamic Allan Variance IV: Characterization of Atomic Clock Anomalies". IEEE Transactions on Ultrasonics, Ferroelectrics, and Frequency Control 62(5): 791-801. DOI: https://doi.org/10.1109/TUFFC.2014.006733. 
7. Gambis Daniel. 2002. "Allan Variance in Earth Rotation Time Series Analysis". Advances in Space Research 30(2): 207-212. DOI: https://doi.org/10.1016/S0273-1177(02)00286-7.

8. Griggs Erin, E. Robert Kursinski, Dennis Akos. 2014. “An Investigation of GNSS Atomic Clock Behavior at Short Time Intervals". GPS Solutions 18(3): 443-452. DOI: https://doi.org/10.1007/s10291-013-0343-7.

9. Griggs Erin, E. Robert Kursinski, Dennis Akos. 2015. "Short-Term GNSS Satellite Clock Stability". Radio Science 50(8): 813-826.

DOI: https://doi.org/10.1002/2015RS005667.

10. Hauschild André, Oliver Montenbruck, Peter Steigenberger. 2013. "Short-Term Analysis of GNSS Clocks". GPS Solutions 17(3): 295-307. DOI: https://doi.org/10.1007/s10291-012-0278-4.

11. Howe D., D. Allan, J. Barnes. 1999. "Properties of oscillator signals and measurement methods". Technical report. Time and Frequency Division. National Institute of Standards and Technnology. Available at: https://tf.nist.gov/phase/Properties/main.htm.

12. Howe D.A., T.K. Peppler. 2001. "Definitions of 'Total' Estimators of Common TimeDomain Variances". In: Proceedings of the 2001 IEEE International Frequncy Control Symposium and PDA Exhibition (Cat. No. 01CH37218), 127-132. IEEE.

DOI: https://doi.org/10.1109/FREQ.2001.956175.

13. Huang Guanwen, Bobin Cui, Yan Xu, Qin Zhang. 2019. "Characteristics and Performance Evaluation of Galileo On-Orbit Satellites Atomic Clocks during 2014-2017". Advances in Space Research 63(9): 2899-2911. DOI: https://doi.org/10.1016/j.asr.2018.01.034.

14. Jakowski Norbert. 2017. Ionosphere Monitoring. Springer Handbooks. DOI: https://doi.org/10.1007/978-3-319-42928-1_39.

15. Kawiecka R., A. Krawczyk, P. Lewińska, K. Pargieła, Stanisław Szombara, A. Tama, K. Adamek, M. Lupa. 2018. "Mining Activity and Its Remains - The Possibilities of Obtaining, Analysing and Disseminating of Various Data on the Example of Miedzianka, Lower Silesia, Poland”. Journal of Applied Engineering Sciences 8(2): 65-72. DOI: https://doi.org/10.2478/jaes-2018-0020.

16. Li Haojun, Xilin Liao, Bofeng Li, Ling Yang. 2018. "Modeling of the GPS Satellite Clock Error and Its Performance Evaluation in Precise Point Positioning". Advances in Space Research 62(4): 845-854. DOI: https://doi.org/10.1016/j.asr.2018.05.025.

17. Li Xingxing, Xinghan Chen, Maorong Ge, Harald Schuh. 2019. "Improving MultiGNSS Ultra-Rapid Orbit Determination for Real-Time Precise Point Positioning". Journal of Geodesy 93(1): 45-64. DOI: https://doi.org/10.1007/s00190-018-1138-y.

18. Li Xingxing, Xin Li, Yongqiang Yuan, Keke Zhang, Xiaohong Zhang, Jens Wickert. 2018. "Multi-GNSS Phase Delay Estimation and PPP Ambiguity Resolution: GPS, BDS, GLONASS, Galileo". Journal of Geodesy 92(6): 579-608. DOI: https://doi.org/10.1007/s00190-017-1081-3.

19. Li Xingxing, Yongqiang Yuan, Jiande Huang, Yiting Zhu, Jiaqi Wu, Yun Xiong, Xin Li, Keke Zhang. 2019. "Galileo and QZSS Precise Orbit and Clock Determination Using New Satellite Metadata”. Journal of Geodesy 93(8): 1123-1136. DOI: https://doi.org/10.1007/s00190-019-01230-4.

20. Ługowska Iwona, Wojciech Woźniak, Teresa Klepacka, Elzbieta Michalak, Katarzyna Szamotulska. 2011. "A Prognostic Evaluation of Vascular Endothelial Growth Factor in Children and Young Adults with Osteosarcoma". Pediatric Blood and Cancer 57(1): 63-68. DOI: https://doi.org/10.1002/pbc.23021. 
21. Lyu Daqian, Fangling Zeng, Xiaofeng Ouyang, Haichuan Zhang. 2020. "Real-Time Clock Comparison and Monitoring with Multi-GNSS Precise Point Positioning: GPS, GLONASS and Galileo". Advances in Space Research 65(1): 560-571. DOI: https://doi.org/10.1016/j.asr.2019.10.029.

22. Maciuk Kamil. 2016. "Different Approaches in GLONASS Orbit Computation from Broadcast Ephemeris". Geodetski Vestnik 60(3): 455-466.

DOI: https://doi.org/10.15292/geodetski-vestnik.2016.03.455-466.

23. Maciuk Kamil, Michał Apollo, Joanna Mostowska, Tomáš Lepeška, Mojca Poklar, Tomasz Noszczyk, Pawel Kroh, Artur Krawczyk, Łukasz Borowski, Polona PavlovčičPrešeren. 2021. "Altitude on Cartographic Materials and Its Correction According to New Measurement Techniques”. Remote Sensing 13(3): 444.

DOI: https://doi.org/10.3390/rs13030444.

24. Marin Razvan Cristian, Antoine Frappe, Andreas Kaiser. 2017. "Delta-Sigma Based Digital Transmitters with Low-Complexity Embedded-FIR Digital to RF Mixing". 2016. IEEE International Conference on Electronics, Circuits and Systems, ICECS 2016: 237-240. DOI: https://doi.org/10.1109/ICECS.2016.7841176.

25. Meng Yansong, Wenying Lei, Lang Bian, Tao Yan, Ying Wang. 2020. “Clock Tuning Technique for a Disciplined High Medium-Long-Stability GNSS Oscillator with Precise Clock Drifts for LEO Users". GPS Solutions 24(4): 1-15.

DOI: https://doi.org/10.1007/s10291-020-01025-7.

26. Montenbruck O., A. Hauschild, S. Häberling, B. Braun, G. Katsigianni, U. Hugentobler. 2017. "High-Rate Clock Variations of the Galileo IOV-1/2 Satellites and Their Impact on Carrier Tracking by Geodetic Receivers". GPS Solutions 21(1): 43-52. DOI: https://doi.org/10.1007/s10291-015-0503-z.

27. Nistor Sorin. 2016. "The Influence of Different Types of Noise on the Velocity Uncertainties in GPS Time Series Analysis". Acta Geodynamica et Geomaterialia 13(4): 387-394. DOI: https://doi.org/10.13168/AGG.2016.0021.

28. Nistor Sorin, Aurelian Stelian Buda. 2016. "GPS Network Noise Analysis: A Case Study of Data Collected over an 18-Month Period". Journal of Spatial Science 61(2): 427-440. DOI: https://doi.org/10.1080/14498596.2016.1138900.

29. Novak A., A Novak Sedlackova, A. Stelmach, D. Novak. 2020. "Safety Implications of GNSS Signal Interference at Zilina Airport". Communications - Scientific Letters of the University of Zilina 22(3): 40-48.

30. Perski A., A. Wieczyński, M. Baczyńska, K. Bożek, S. Kapelko, S. Pawłowski. 2013. “Odbiorniki GNSS w praktyce inżynierskiej”. [In Polish: „GNSS receivers in engineering practice"']. Pomiary Automatyka Robotyka 17(3): 64-77.

31. Dang Bao An Tran. 2019. "Laser a Cascade Quantique stabilise sur peigne de frequence, largement accordable et calibre au SI: application a la spectroscopie de tres haute precision de molecules polyatomiques". [In French: "Quantum cascade laser stabilized on a frequency comb, largely tunable and calibrated to the SI: application to very high precision spectroscopy of polyatomic molecules"]. Doctoral dissertation. Laboratoire De Physique Des Lasers CNRS UMR7538, Universite Paris 13, Institut Galilee.

32. Quasi-Zenith Satellite System. 2020. "List of Positioning Satellites".

33. Rabbou Mahmoud Abd, Ahmed El-rabbany. 2016. "Single-frequency precise point positioning using multi-constellation GNSS: GPS, GLONASS, GALILEO and BeiDou". Geomatica 70(2): 113-122. 
34. Roberts Gethin Wyn. 2019. "Noise Comparison of Triple Frequency GNSS Carrier Phase, Doppler and Pseudorange Observables". Measurement: Journal of the International Measurement Confederation 144: 328-344.

DOI: https://doi.org/10.1016/j.measurement.2019.05.011.

35. Rutkowski Rob. 2019. "What's The Differences between the 5 GNSS Constellations?". Available at: https://blog.bliley.com/the-differences-between-the-5-gnss-satellitenetwork-constellations.

36. Saleh Hussain Aziz, Rachid Chelouah. 2004. "The Design of the Global Navigation

Satellite System Surveying Networks Using Genetic Algorithms". Engineering

Applications of Artificial Intelligence 17(1): 111-122.

DOI: https://doi.org/10.1016/j.engappai.2003.11.001.

37. "Section Four". 1980. The Journal of American Culture 3(1). 104 p.

DOI: https://doi.org/10.1111/j.1542-734x.1980.0301_104.x.

38. Shi Chuang, Shiwei Guo, Shengfeng Gu, Xinhao Yang, Xiaopeng Gong, Zhiguo Deng, Maorong Ge, Harald Schuh. 2019. "Multi-GNSS Satellite Clock Estimation Constrained with Oscillator Noise Model in the Existence of Data Discontinuity". Journal of Geodesy 93(4): 515-528. DOI: https://doi.org/10.1007/s00190-018-1178-3.

39. Stefani Raymond T. 2004. Stability Analysis. The Engineering Handbook. Second Edition. DOI: https://doi.org/10.1525/9780520951785-119.

40. Steigenberger Peter, Steffen Thoelert, Oliver Montenbruck. 2020. “GPS III Vespucci: Results of Half a Year in Orbit". Advances in Space Research. DOI: https://doi.org/10.1016/j.asr.2020.03.026.

41. Thoelert Steffen, Oliver Montenbruck, Michael Meurer. 2014. "IRNSS-1A: Signal and Clock Characterization of the Indian Regional Navigation System". GPS Solutions 18(1): 147-152. DOI: https://doi.org/10.1007/s10291-013-0351-7.

42. Walter Todd, Kazuma Gunning, R. Eric Phelts, Juan Blanch. 2018. "Validation of the Unfaulted Error Bounds for ARAIM". Navigation, Journal of the Institute of Navigation 65(1): 117-133. DOI: https://doi.org/10.1002/navi.214.

43. Xie Wei, Guanwen Huang, Bobin Cui, Pingli Li, Yu Cao, Haohao Wang, Zi Chen, Bo Shao. 2019. "Characteristics and Performance Evaluation of QZSS Onboard Satellite Clocks". Sensors 19(23). DOI: https://doi.org/10.3390/s19235147.

44. Xu Chang, D. Yue. 2017. "Characterizing Noise in Daily GPS Position Time Series with Overlapping Hadamard Variance and Maximum Likelihood Estimation”. Survey Review 49(355): 239-248. DOI: https://doi.org/10.1080/00396265.2016.1163830.

45. Yang H., Chang Xu, Y. Gao. 2019. "Analysis of GPS Satellite Clock Prediction Performance with Different Update Intervals and Application to Real-Time PPP". Survey Review 51(364): 43-52. DOI: https://doi.org/10.1080/00396265.2017.1359473.

46. Ye Zhen, Haojun Li, Sanjun Wang. 2021. "Characteristic Analysis of the GNSS Satellite Clock". Advances in Space Research 68(8): 3314-3326.

DOI: https://doi.org/10.1016/j.asr.2021.06.030.

47. Yunck Thomas P., William G. Melbourne, C.L. Thornton. 1985. "GPS-Based Satellite Tracking System for Precise Positioning”. IEEE Transactions on Geoscience and Remote Sensing GE-23(4): 450-457. DOI: https://doi.org/10.1109/TGRS.1985.289434.

48. Zucca Cristina, Patrizia Tavella. 2005. "The Clock Model and Its Relationship with the Allan and Related Variances". IEEE Transactions on Ultrasonics, Ferroelectrics, and Frequency Control 52(2): 289-295.

DOI: https://doi.org/10.1109/TUFFC.2005.1406554. 
Received 09.10.2021; accepted in revised form 26.11.2021

$$
\text { (c) (i) }
$$

Scientific Journal of Silesian University of Technology. Series Transport is licensed under a Creative Commons Attribution 4.0 International License 